\title{
O PARFOR NO CONTEXTO DA POLÍTICA NACIONAL DE FORMAÇÃO DE PROFISSIONAIS DO MAGISTÉRIO DA EDUCAÇÃO BÁSICA
}

\author{
Nathanael da Cruz e Silva Neto ${ }^{1}$, Julio Cesar Torres ${ }^{2}$ \\ ${ }^{1}$ Mestre em Educação e Doutorando pelo Programa de Pós-Graduação em Educação da Universidade Estadual Paulista - UNESP, Marília, SP. E-mail: \\ ncsilvaneto@gmail.com \\ ${ }^{2}$ Doutor em Sociologia pelo Programa de Pós-Graduação em Sociologia da Universidade Estadual Paulista - UNESP, Araraquara. Professor do \\ Departamento de Educação da UNESP/São José do Rio Preto, e do Programa de Pós-Graduação em Educação da UNESP/Marília, SP.
}

\section{RESUMO}

O objetivo deste trabalho é realizar uma breve análise do Plano Nacional de Formação de Professores da Educação Básica (Parfor), instituído em 2009 no âmbito da Política Nacional de Formação de Profissionais do Magistério da Educação Básica, sob responsabilidade da Capes. Trata-se de pesquisa bibliográfica e documental, amparada por estudos sobre formação docente no Brasil e sobre o papel da Capes em políticas dessa natureza, bem como nos relatórios de gestão do referido órgão. Constatamos que, embora tal Programa constitua avanço relativamente às necessidades formativas para a docência na Educação Básica, seu caráter pulverizado compromete a abrangência dessa política pública.

Palavras-chave: Política Educacional; Formação de Professores; Educação Básica; Parfor; Capes.

\section{PARFOR IN THE CONTEXT OF THE NATIONAL POLICY OF TRAINING OF PROFESSIONALS OF THE MAGISTRARY OF BASIC EDUCATION}

\section{ABSTRACT}

This paper aims at analyzing the Formation of Teachers of Elementary Education National Plan (Parfor), which was instituted in 2009 on the context of the National Policy of Formation of Teaching Professionals of Elementary Education, under the responsibility of Capes. It is a bibliographical and documentary research supported by studies on teacher education in Brazil and on the role of Capes in policies of this nature, as well as management documents of this institution. We found that although such a Program constitutes some progress in relation to the formation needs for teaching in Elementary Education, its pulverized character compromises a coverage of this public policy.

Keywords: Educational policy; Formation of Teachers; Elementary Education; Parfor; Capes.

\section{Apontamentos iniciais}

O presente estudo pretende realizar uma breve análise do Plano Nacional de Formação de Professores da Educação Básica (Parfor) no contexto da Política Nacional de Formação de Profissionais do Magistério da Educação Básica, sob responsabilidade da Coordenação de Aperfeiçoamento de Pessoal de Nível Superior (Capes).

Essa política foi instituída pelo Decreto no $6755^{1}$, no dia 29 de janeiro de 2009. Entre outras

\footnotetext{
${ }^{1}$ Esse decreto foi revogado, recentemente, pelo Decreto no 8752 , de 9 de maio de 2016. O texto do novo decreto sugere uma diminuição drástica da participação da Capes nos programas e ações, indicando que caberá ao MEC desenvolver o Planejamento Estratégico Nacional, aprovado por um Comitê Gestor Nacional e com duração quadrienal. A Capes é mencionada como responsável
}

providências, o instrumento legal disciplina a atuação da Coordenação de Aperfeiçoamento de Pessoal de Nível Superior (Capes) no fomento a programas de formação inicial e continuada de docentes da Educação Básica. Tradicionalmente voltado a questões relativas à pós-graduação no Brasil, o órgão passa por diversas modificações, tanto em sua estrutura quanto em seu campo de atuação, de modo a se adequar ao cumprimento do decreto. A partir de então, passa a ser chamado de Nova Capes pelos pesquisadores da área. Vários programas voltados à formação

apenas pelo fomento à pesquisa aplicada nas licenciaturas e nos programas de pós-graduação, destinada à investigação dos processos de ensino-aprendizagem e ao desenvolvimento da didática específica. Tal quadro leva-nos ao questionamento de um possível fim da Capes para a Educação Básica (BRASIL, 2016a). 
inicial, continuada e à valorização do magistério são lançados no âmbito de sua nova diretoria, criada para esse fim, a Diretoria de Formação de Professores da Educação Básica (DEB). Ademais, outras iniciativas, já existentes no interior do MEC e voltadas à formação docente dessa etapa de escolarização, passam a ser de sua competência.

A pesquisa é um recorte de uma pesquisa maior, desenvolvida em nível de Mestrado, que buscou discutir os principais programas da Capes voltados à formação de professores da Educação Básica, e foi desenvolvida com base nos pressupostos da pesquisa bibliográfica e documental. Além do apoio da literatura pertinente aos estudos sobre formação de professores no Brasil e sobre a trajetória e o papel desempenhado pela Capes nas políticas de formação de profissionais do magistério da Educação Básica, valemo-nos, para nosso estudo, de documentos e dados provenientes da própria Capes, e mais especificamente, dos relatórios de gestão da sua diretoria que nos interessa no âmbito deste estudo, a DEB.

\section{Antecedentes da Política Nacional de Formação de Professores}

Ao longo da história da educação brasileira, nota-se um crescente debate acerca de políticas públicas voltadas à Educação Básica. $\mathrm{A}$ formação de professores é um dos aspectos centrais, que vem protagonizando boa parte da agenda das políticas educacionais contemporâneas.

No Brasil, entretanto, a carreira docente não vem acompanhada de prestígio social. De acordo com dados do último Censo da Educação Superior, o número de brasileiros cursando o Ensino Superior vem crescendo, porém a quantidade de pessoas ingressando em carreiras ligadas à docência não cresce na mesma proporção. De 2012 para 2013, o número total de matrículas em cursos de graduação cresceu $3,8 \%$, mas, no caso das licenciaturas, o percentual de crescimento foi de apenas $0,55 \%$, concentrando o restante nos bacharelados e tecnológicos. Além disso, as licenciaturas permanecem, majoritariamente, entre os cursos com menor relação candidato/vaga nos processos seletivos de ingresso (TORRES et al., 2013, p. 3).

Tal desinteresse pela profissão pode ser explicado por inúmeros fatores. De acordo com o estudo de Caldas (2007), sobre o abandono da profissão docente de professores da rede municipal de educação de Curitiba (PR), estão, entre os principais fatores: baixos salários, problemas físicos e psicológicos, infraestrutura precária, violência no ambiente de trabalho, pressão e cobrança pelos resultados e sentimento de desvalorização da profissão pela sociedade. De fato, o baixo prestígio social da profissão docente se reflete na baixa relação candidato/vaga nos exames de ingresso, bem como na concentração de excedente de vagas nos cursos de licenciatura, conforme apontam Torres e Pagotto (2013). Ademais, os problemas apontados por Caldas (2007) são velhos conhecidos, temas que circulam diariamente pela mídia e afugentam os ingressantes em cursos de licenciatura. Em alternativa, muitos deles acabam por seguir outros caminhos que não a docência.

Contudo, faz-se importante uma pequena ressalva com relação a tal desprestígio social. Da perspectiva das classes médias e altas, a profissão docente, de fato, não representa carreira de prestígio, haja vista que se observa grande procura por cursos elitistas, tais como medicina, direito, engenharias, entre outros. No caso das licenciaturas, quando se observa o contexto socioeconômico de onde provêm os estudantes, estudos demonstram que se trata, em sua maioria, de alunos provenientes de escolas públicas, de classe média e baixa e filhos de pais com baixo nível de escolaridade. Não são raros casos em que os licenciandos representem o primeiro membro da família a ingressar no ensino superior. Nesse sentido, pode-se afirmar que tal formação constitui uma conquista profissional de grande valor. ${ }^{2}$

Somados à questão do desinteresse, encontramos também os problemas observados após o ingresso em um curso de formação de professores. No final dos anos 1930 e início dos anos 1940, em razão da falta de professores, acrescentava-se à formação de bacharéis, para obterem a habilitação para o magistério, um ano de disciplinas da área de Educação, modelo que se denominou popularmente " $3+1$ " (GATTI, 2010, p. 1356). Tal modelo demonstra, de maneira clara, a desarticulação teoria/prática presente na formação de professores, problemática existente ainda hoje nos cursos de licenciatura. Entretanto, note-se que muitos estudantes de licenciatura recorrem aos chamados "estágios remunerados", cujo auxílio

\footnotetext{
${ }^{2}$ Com relação ao perfil socioeconômico de licenciandos, é possível consultar Torres et al. (2013), Santos et al. (2014), Pizoni (2014), entre outros.
} 
financeiro proporciona o incremento da própria renda familiar. Nesses casos, embora possa, muitas vezes, não haver supervisão que promova a reflexão sobre a atuação nos estabelecimentos de ensino, não se pode afirmar que não haja vivência profissional que constitua prática docente concomitante com a formação teórica.

Há que de discutir também a deficiência, inadequação ou mesmo a ausência de formação superior entre os docentes que atuam na Educação Básica. A Lei de Diretrizes e Bases da Educação Nacional (LDBEN), Lei no 9394, de 20 de dezembro de 1996, estabeleceu a obrigatoriedade da formação desse professor em nível superior. Disso resultou, consequentemente, o aumento acelerado de cursos de licenciatura voltados para a formação de professores da Educação Básica, sobretudo para a Educação Infantil e as séries iniciais do Ensino Fundamental (GATTI; BARRETO, 2009). Ainda assim, continuamos a evidenciar a falta de professores sem formação adequada para atuar nos Ensinos Fundamental e Médio, sendo que, muitos deles, sequer possuem formação superior (MAZZETTO; BRAVO; CARNEIRO, 2002).

É importante referir, ainda, a questão da permanência daqueles que ingressam em cursos de formação docente. Levando-se em consideração o baixo prestígio social da profissão, a baixa relação candidato/vaga e, ainda, a formação deficiente dos alunos do Ensino Médio, é possível que o perfil socioeconômico dos estudantes de licenciatura possa vir a interferir nos índices de evasão e, com isso, de concluintes (TORRES; PAGOTTO, 2014). Assim, continuamos a enfrentar os problemas de escassez de professores em sala de aula, levando a medidas que prejudicam o próprio ensino, como admitir a docência de professores em disciplinas que não são objetos de sua formação (as chamadas "correlatas"), ou mesmo permitir o exercício da docência a profissionais sem formação superior, contrariando a legislação e as instruções normativas.

O Plano Nacional de Educação (PNE), que havia sido elaborado em 1996 e 1997, foi instituído pela Lei no 10.172, de 9 de janeiro de 2001, e vigorou por 10 anos. No texto da lei, na seção que aborda as questões do magistério da Educação Básica, são estabelecidos 28 objetivos e metas para a formação dos professores e a valorização do magistério. Tais metas tinham como princípio estruturante a instituição de uma política global de magistério que implicasse a formação profissional inicial, as condições de trabalho, salário e carreira, e a formação continuada.

No entanto, o plano não foi cumprido à risca, mas seus anos de vigência culminaram com a realização, em 2010, da Conferência Nacional de Educação (Conae), em Brasília, na qual o plano foi refeito e aprimorado para que as metas fossem alcançadas entre 2011 e 2020. Por questões que envolvem conflitos de interesses e jogos de poder na arena política, o trâmite do projeto no Congresso Nacional foi bastante estendido, e, por isso, a Lei no 13.005, que o aprova, publicada em 25 de junho de 2014, modificou a vigência do plano para o decênio 2014-2024. Dentre as 20 metas que o constituem, 3 são voltadas para a questão da formação docente, a saber:

- Meta 15 - Formação de professores: para assegurar que todos os professores da Educação Básica possuam formação específica de nível superior, obtida em curso de licenciatura na área de conhecimento em que atuam;

- Meta 16 - Formação continuada e pós-graduação de professores: para garantir a todos os profissionais da Educação Básica formação continuada em sua área de atuação, considerando as necessidades, demandas e contextualizações dos sistemas de ensino.

- Meta 17 - Valorização do professor: para equiparar o rendimento médio dos docentes ao dos demais profissionais com escolaridade equivalente.

Em 2007, o Ministério da Educação (MEC) publicou o Plano de Desenvolvimento da Educação (PDE), no âmbito do Programa de Aceleração do Crescimento (PAC), criado no segundo mandato do Governo Lula (2007-2010). O propósito era constituir uma ferramenta de prestação de contas da qualidade de ensino, de monitoramento do desenvolvimento das ações do PNE e de execução de novas ações em favor da melhoria da educação. Saviani (2007) considera que o PDE "aparece como um grande guarda-chuva que abriga praticamente todos os programas em desenvolvimento pelo MEC". Além disso, o Plano também assume a agenda do "Compromisso Todos pela Educação", que havia 
sido lançado no ano anterior, como uma iniciativa da sociedade civil.

Por sua vez, profissionais, pesquisadores e especialistas em educação brasileiros também indicaram a necessidade de atenção às questões concernentes à formação e à valorização da profissão docente. Tais apontamentos foram feitos por meio de estudos, diagnósticos e relatórios da situação educacional do país, como o documento Escassez de professores no Ensino Médio: propostas estruturais e emergenciais, publicado em 2007 pelo Conselho Nacional de Educação (CNE), abordando a falta de professores no Ensino Médio, especialmente das áreas de exatas e de biológicas, fenômeno que, à época, foi cunhado de "apagão educacional". Em consequência disso, também foi apresentado, pelo Diretor de Estatísticas e Avaliação da Educação Superior do INEP, o relatório intitulado As licenciaturas e o Ensino Básico brasileiro: diagnóstico, mostrando que muitos dos problemas apontados no diagnóstico anterior também se aplicavam ao Ensino Fundamental, além de outras questões que precisavam ser consideradas no âmbito das políticas educacionais (RISTOFF, 2011). Enfim, os documentos apontavam que a questão da formação docente demandava uma política de alcance nacional, que pudesse apoiar a formação de quadros qualificados para o exercício da docência.

Nota-se, portanto, que diversos setores normativas legais, especialistas e pesquisadores da área e iniciativas da sociedade civil apontaram para a necessidade de uma proposta verdadeiramente articulada e abrangente de formação docente e valorização do magistério da Educação Básica, o que se daria por meio da instituição de uma Política Nacional. Assim, a estrutura da Capes foi modificada e tal política passou a ser implementada por meio de Programas lançados e financiados pela coordenadoria via editais, junto às Universidades e articulados com os estabelecimentos de ensino dessa etapa de escolarização. Um de seus programas mais expoentes foi o Parfor, que passa a ser discutido a seguir.

\section{O Plano Nacional de Formação de Professores da Educação Básica - Parfor}

O Parfor foi lançado em 2009, como uma ação emergencial destinada à formação de professores em serviço. A motivação para a criação desse Programa foi a quantidade de docentes lecionando na Educação Básica sem Ensino Superior. Scheibe (2010, p. 986) indica que, em 2009, o país contava com 600 mil professores sem formação considerada adequada ao trabalho. De acordo com dados do Censo Escolar, obtidos por meio do Observatório do PNE, 32,2\% dos professores da Educação Básica não possuíam Ensino Superior naquele mesmo ano. Há que se levar em conta as implicações negativas de tal quadro, já que, quanto maior o percentual de docentes atuando com formação inadequada, menor é a nota do IDEB (FERRO, 2013).

Além disso, as Leis no $12.056 / 2009$ e no $12.796 / 2013$ alteraram alguns dispositivos da LDBEN, incluindo algumas considerações específicas sobre a formação mínima para os docentes da Educação Básica (Ensino Superior, em cursos de licenciatura plena, sendo admitida a formação em nível médio na modalidade normal para a Educação Infantil e os 5 primeiros anos do Ensino Fundamental), além de estabelecer o compromisso do governo de "adotar mecanismos facilitadores de acesso e permanência em cursos de formação de docentes em nível superior para atuar na educação básica pública". Assim, o Parfor aparece também como um mecanismo para garantir ao professorado da Educação Básica a formação exigida pela LBDEN.

O Programa fomenta turmas especiais voltadas exclusivamente para professores em exercício na rede pública de Educação Básica, em três modalidades diferentes:

- Primeira Licenciatura: para docentes ou tradutores/intérpretes de Libras que não têm formação em nível superior ou que, mesmo tendo essa formação, queiram realizar curso de licenciatura na disciplina ou na etapa em que atuam em sala de aula;

- Segunda Licenciatura: para professores licenciados que atuam em área distinta da sua formação inicial, ou para profissionais licenciados que atuam como tradutor/intérprete de Libras;

- Formação Pedagógica: para docentes ou tradutores intérpretes de Libras graduados, mas não licenciados;

Dentre esses três tipos de turmas especiais oferecidas pelo Parfor, o Primeira Licenciatura é o mais ofertado, revelando que a formação inicial em ensino superior para 
docentes já em atuação constitui a prioridade dessa política. Segundo dados da DEB/Capes, a oferta dos cursos do Parfor, até o ano de 2014, está distribuída conforme mostra o gráfico 9. As porcentagens correspondem a um total de 2.428 turmas, em 451 municípios diferentes, e a um total de 79.060 matrículas.

Gráfico 1. Oferta de cursos do Parfor por tipo de turma (2009-2014)

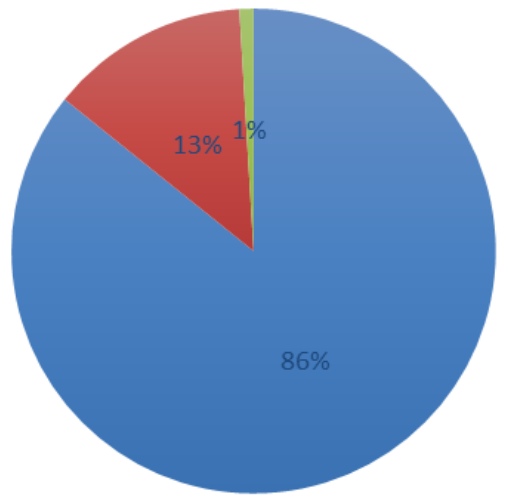

- Primeira Licenciatura

- Segunda licenciatura

- Formação Pedagógica

Fonte: Elaboração própria, 2017 - a partir dos dados do Relatório de Gestão Capes/DEB 2009-2014.

Os princípios pedagógicos do Parfor compartilham dos mesmos princípios proclamados no âmbito da Política Nacional, evidenciados no Artigo 2o do decreto que a instituiu. Tais concepções devem orientar 0 planejamento pedagógico das instituições de ensino que ofertam os cursos do Parfor:

- A articulação entre teoria e prática em todo o percurso formativo;

- A garantia do domínio de conhecimentos científicos e didáticos;

- A indissociabilidade entre ensino, pesquisa e extensão; e

- O reconhecimento da escola como espaço necessário à formação inicial dos profissionais do magistério.

A observância desses princípios visa a reunir condições para se efetivarem os objetivos do Programa, que se articulam com os objetivos da Política Nacional, em busca de elevar a qualidade da formação docente nas escolas de Educação Básica.

Assim como referido na própria $\mathrm{LDBEN}$, a formação inicial de profissionais do magistério deve ser, preferencialmente, por meio do ensino presencial, e a formação continuada pode utilizar recursos e tecnologias de educação a distância (EaD). Partindo desse pressuposto, o Parfor Primeira Licenciatura é oferecido na modalidade presencial, enquanto o Parfor Segunda Licenciatura e a Formação pedagógica, no âmbito da EaD. Assim, a implementação dos cursos presenciais na Capes é realizada pela DEB. Os cursos de formação continuada encontram-se sob responsabilidade da DED, sendo geridos, a partir de 2012, pelo sistema de gestão da Universidade Aberta do Brasil (UAB).

Sua operacionalização se dá por meio de Acordos de Cooperação Técnica (ACTs) entre a Capes e as Secretarias Estaduais de Educação. Quantos às IES, a participação é efetivada por meio de assinatura de Termo de Adesão ao ACT, para a oferta de cursos na modalidade presencial. Segundo dados do Relatório de Gestão da DEB/Capes 2009-2014, foram firmados ACTs com 26 estados e o Distrito Federal, tendo 142 IES participantes.

Para estarem habilitadas a oferecer turmas do Parfor, as IES devem apresentar Índice Geral de Cursos com conceito igual ou superior a 3 e, ainda, o curso de licenciatura no qual a turma especial será implantada também deve ter índice igual ou superior a 3 . No caso de IES que não fazem parte do sistema federal, deve ser apresentado documento de autorização dos cursos pelo órgão estadual competente.

O programa também possibilita o credenciamento de instituições privadas. Quando a oferta de vagas por instituições públicas não for suficiente para atender à demanda por formação inicial dos professores em exercício, podem participar IES privadas sem fins lucrativos, mediante edital realizado pela Capes. O levantamento de tais necessidades e a solicitação/justificativa deve ser elaborada pelo 
respectivo Fórum Estadual. Com relação à participação dos professores em exercício nesses cursos de formação, esta deve ser formalmente autorizada pelo secretário de educação, que também atesta $\mathrm{o}$ atendimento aos requisitos exigidos pelo programa.
De acordo com o Relatório da DEB, o ano de 2014 terminou contabilizando 99 IES participantes, sendo sua distribuição regional conforme o gráfico 10.

Gráfico 2. Número de IES participantes do Parfor em 2014, por região

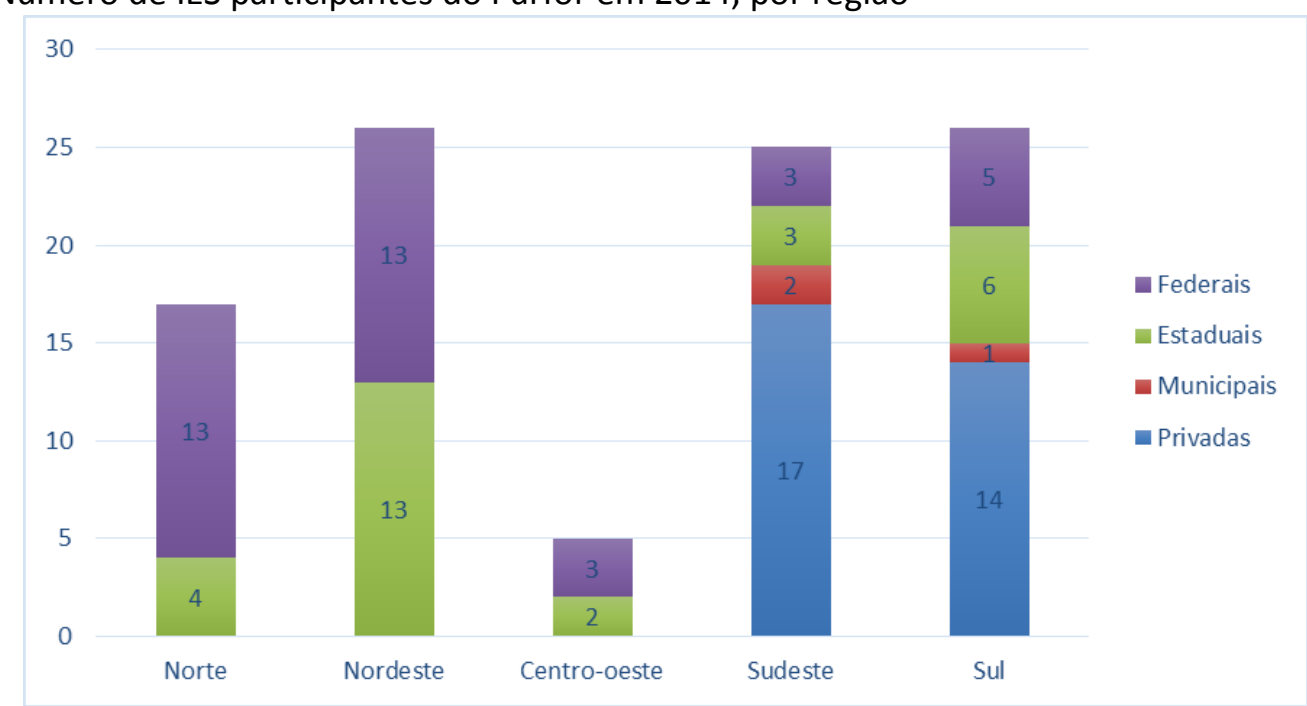

Fonte: Elaboração própria, 2017 - a partir dos dados do Relatório de Gestão Capes/DEB 2009-2014.

Percebe-se que o número de IES participantes é liderado, concomitantemente, pelas regiões Nordeste e Sul, com 26 instituições, estando a Sudeste apenas um pouco atrás, com 25. Logo em seguida, a região Norte aparece com 17 instituições. A região Centro-oeste é a que apresenta menor expressividade em termos de instituições participantes, com 5.

Outro dado interessante de se observar é que as regiões Norte, Nordeste e Centro-oeste concentram o Parfor em instituições públicas federais e estaduais, sendo que, nas duas últimas regiões, a proporção entre federais e estaduais é equivalente. $\mathrm{Em}$ contrapartida, nas regiões Sudeste e Sul, apesar da presença também de instituições públicas da esfera municipal, há predominância do programa nas instituições privadas, principalmente no Sudeste.

No próximo gráfico, apresentamos dados sobre matrículas ativas e sobre IES participantes, dessa vez, de forma percentual. 
Gráfico 3. Percentual de IES participantes e matrículas ativas do Parfor em 2014, por região geográfica

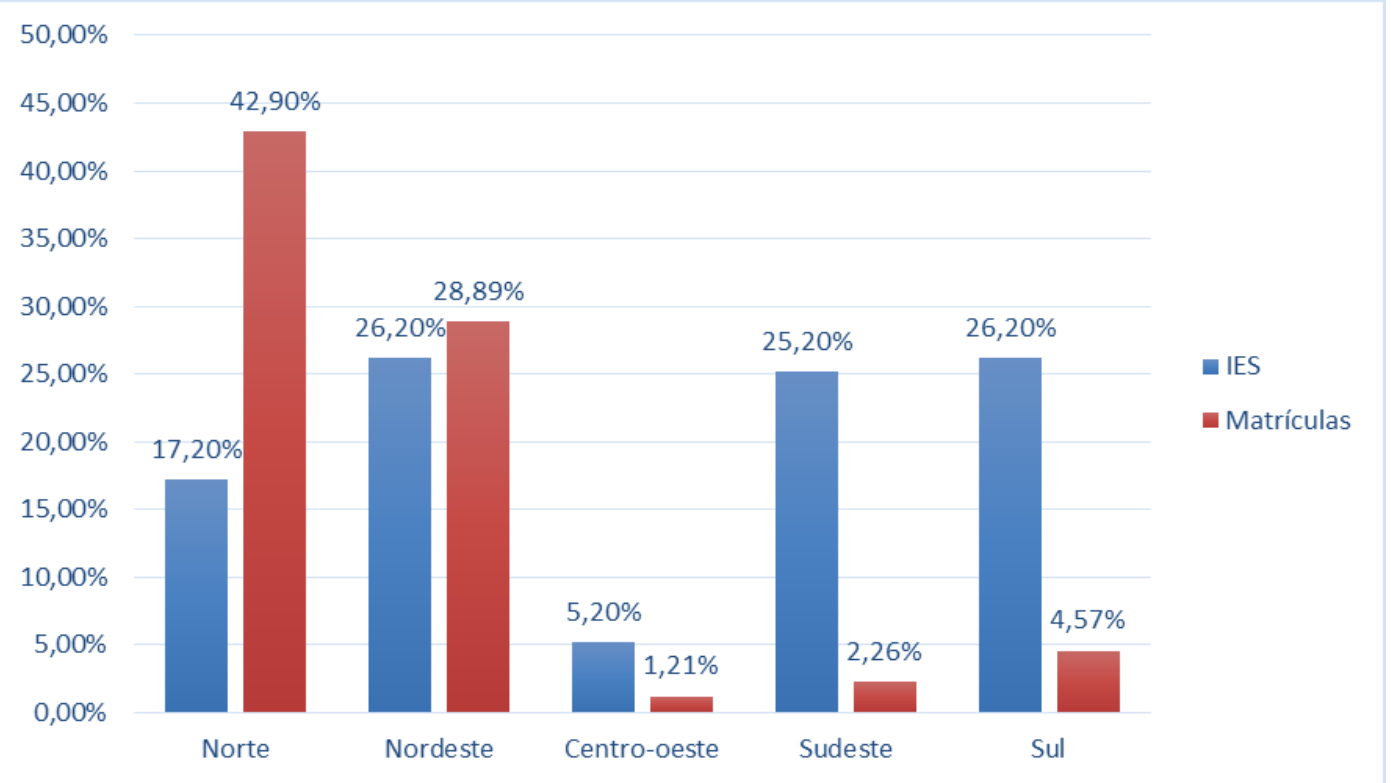

Fonte: Elaboração própria, 2017 - a partir dos dados do Relatório de Gestão Capes/DEB 2009-2014.

Embora não seja esta a região com mais IES participantes, o número de matrículas encontra sua maioria no Norte, que concentra $42,9 \%$ delas. Em seguida, aparece o Nordeste, com $28,89 \%$ das matrículas. O menor número de matrículas está na região Centro-oeste $(1,21 \%)$. Contudo, esse número não é tão discrepante quanto no Sul e no Sudeste, regiões que concentram grande parte das instituições, mas apresentam baixo percentual das matrículas, principalmente o Sudeste. Tais números revelam que não há correspondência entre IES participantes e matrículas efetivadas nas turmas especiais do Parfor.

Ao se considerarem todas as matrículas do período de 2009 a 2014, o quadro não se mostra muito diferente, conforme pode ser observado na tabela 4. Saliente-se que os estados de Alagoas, Sergipe e Goiás não abrigaram cursos do Parfor (ainda que Goiás possua professores matriculados em cursos no Distrito Federal).

Tabela 1. Número de matrículas e de turmas no Parfor por região (2009 a 2014)

\begin{tabular}{ccc|}
\hline Região & Matrículas & Turmas implantadas \\
\hline Norte & $38.994(47,62 \%)$ & 1.156 \\
\hline Nordeste & $30.110(37,64 \%)$ & 914 \\
\hline Centro-oeste & $1.316(2,22 \%)$ & 54 \\
\hline Sudeste & $2.904(3,75 \%)$ & 213 \\
\hline Sul & $5.736(8,77 \%)$ & 91 \\
\hline TOTAL & $\mathbf{7 9 . 0 6 0}$ & $\mathbf{2 . 4 2 8}$ \\
\hline
\end{tabular}

Fonte: Elaboração própria, 2017 - a partir dos dados do Relatório de Gestão Capes/DEB 2009-2014.

No ano de 2009, em que se iniciou a implementação do Parfor, o país contava com quase $70 \%$ dos seus docentes de Educação Básica com curso de nível superior, sendo 3,2\% desses sem licenciatura. Embora esse percentual pareça baixo, há que se levar em consideração que, de acordo com o Censo Escolar, no referido ano, o Brasil contava com 1.977.978 docentes. Ao se observar os índices de cada região, percebem-se as necessidades formativas de cada uma delas. 
Tabela 2. Professores da Educação Básica com nível superior, com e sem licenciatura, por região geográfica (2009)

\begin{tabular}{ccccc}
\hline Região & $\begin{array}{c}\text { Professores } \\
\text { da } \\
\text { Educação } \\
\text { Básica }\end{array}$ & $\begin{array}{c}\text { Professores } \\
\text { com nivel } \\
\text { superior }\end{array}$ & $\begin{array}{c}\text { Professores } \\
\text { com } \\
\text { licenciatura }\end{array}$ & $\begin{array}{c}\text { Professores } \\
\text { sem } \\
\text { licenciatura }\end{array}$ \\
\hline Norte & 166.009 & $54 \%$ & $47,5 \%$ & $6,5 \%$ \\
\hline Nordeste & 598.703 & $48,7 \%$ & $46 \%$ & $2,6 \%$ \\
\hline Centro- & 140.948 & $79,6 \%$ & $76,5 \%$ & $3,1 \%$ \\
oeste & & $79 \%$ & & $2,2 \%$ \\
\hline Sudeste & 786.179 & $78,9 \%$ & $73,8 \%$ & $5 \%$ \\
\hline Sul & 286.139 & $67,7 \%$ & $64,6 \%$ & $3,2 \%$ \\
\hline BRASIL & 1.977 .978 & & $73 \%$ & \\
\hline
\end{tabular}

Fonte: Elaboração própria, 2017 - a partir dos dados do Relatório de Gestão Capes/DEB 2009-2014.

Ao se observar tal quadro, constata-se que a região que apresentava maiores necessidades formativas era a Norte, com o maior índice de professores sem licenciatura. Entretanto, a segunda região com maior número de docentes não licenciados é o Sul, mas que aparece em 3ㅇ lugar com relação ao número de matrículas do Parfor. Observa-se, pois, que não há relação direta entre índices de professores não licenciados e matrículas do programa.
É fundamental observar também a distorção área de formação e área de atuação. A tabela seguinte apresenta o percentual de professores com formação compatível nas áreas em que lecionam, de acordo com dados referentes ao ano de 2012.

Tabela 3. Professores da Educação Básica com formação superior compatível com a área/disciplinas em que lecionam (2012)

\begin{tabular}{ccccccc}
\hline Região & $\begin{array}{c}\text { Formação } \\
\text { compativel com } \\
\text { todas as } \\
\text { disciplinas }\end{array}$ & \multicolumn{2}{c}{$\begin{array}{c}\text { Formação } \\
\text { compativel pelo } \\
\text { menos uma das } \\
\text { disciplinas }\end{array}$} & \multicolumn{2}{c}{$\begin{array}{c}\text { Sem formação } \\
\text { compativel com } \\
\text { qualquer disciplina }\end{array}$} \\
\hline EF & EM & EF & EM & EF & EM \\
\hline Norde & $29,4 \%$ & $48 \%$ & $12,1 \%$ & $19,3 \%$ & $58,5 \%$ & $32,8 \%$ \\
\hline Centro- & $42,9 \%$ & $43,2 \%$ & $15,2 \%$ & $19 \%$ & $41,8 \%$ & $37,8 \%$ \\
oeste & & $37,6 \%$ & $16 \%$ & $18,9 \%$ & $60,5 \%$ & $43,5 \%$ \\
\hline Sudeste & $59,7 \%$ & $57,6 \%$ & $7,6 \%$ & $9,6 \%$ & $32,6 \%$ & $32,8 \%$ \\
\hline Sul & $54,5 \%$ & $57,9 \%$ & $16,5 \%$ & $15,1 \%$ & $29 \%$ & $27,1 \%$ \\
\hline BRASIL & $\mathbf{4 3 , 6 \%}$ & $\mathbf{5 0 , 9} \%$ & $\mathbf{1 2 , 5 \%}$ & $\mathbf{1 4 , 2} \%$ & $\mathbf{4 4} \%$ & $\mathbf{3 4 , 9} \%$ \\
\hline
\end{tabular}

Fonte: Elaboração própria, 2017 - a partir dos dados do Relatório de Gestão Capes/DEB 2009-2014.

Esses dados permitem verificar, com mais

precisão, a proporção de professores da
Educação Básica sem formação adequada para a área em que atuam. Contava-se, no referido ano, 
com $44 \%$ dos professores dos anos finais do Ensino Fundamental sem formação adequada, enquanto no Ensino Médio, 34,9\%. De modo geral, em todas as regiões, percebe-se que o percentual de professores sem formação adequada prevalece maior no Ensino Fundamental, com exceção da região Sudeste, que praticamente mantêm iguais os índices para as duas etapas de Ensino. É perceptível, também, que o Norte e o Nordeste são os estados que mais apresentam diferenças entre os índices de professores adequadamente formados se comparados o Ensino Fundamental e o Médio. Com base nos dados da tabela 6 , é possível afirmar, pois, que a região com maiores necessidades formativas de seus docentes, nas etapas de ensino indicadas, passa a ser a região Nordeste, quadro diferente do apontado quando se analisaram os professores sem licenciatura no ano de 2009 (tabela 5). Como o Relatório da DEB não apresenta $\mathrm{o}$ quantitativo regional de matrículas do Parfor por ano, não é possível verificar se esses indicadores foram levados em consideração para a oferta de matrículas do programa a partir de 2012. Com base nos dados totais, de que dispomos, sugere-se que não houve a articulação de tais indicadores no desenvolvimento do programa.

Faz-se necessário mencionar, ainda, que, de acordo com o Relatório da DEB, o número total de matrículas efetivadas no Parfor corresponde a apenas $27,45 \%$ do total de vagas ofertadas, mostrando que, de fato, há inadequação entre oferta e demanda. Uma das explicações pode ser a falta de estímulo aos docentes para participarem do programa e adequarem sua formação. Além disso, conforme já mencionado no início deste trabalho, é registrada a queda da procura por cursos de licenciatura, além da evasão, sobretudo de cursos das áreas de Ciências Exatas e de Biológicas. De acordo com estudo de Rabelo (2015, p. 104), baseado em dados do Censo da Educação Superior de 2013, a taxa de conclusão de cursos de licenciatura em Biologia foi de 42,6\%. Nas áreas de Matemática e Química, apenas um em cada três licenciandos obtêm o diploma $(34,1 \%$ e $33,9 \%)$. A mais preocupante é a área de Física, com taxa de conclusão de apenas $20,5 \%$ dos ingressantes.

Mostra-se interessante, também, apresentar alguns dados relativos às condições de permanência nos cursos do Parfor. Com base em questionários aplicados a 4.560 discentes do
Programa, foi verificado que há dificuldades encontradas pelos alunos tanto para a liberação do trabalho quanto na concessão de apoio institucional por parte das secretarias de educação. Com relação ao primeiro, $71 \%$ afirmaram possuir liberação para participar dos cursos. Quanto ao apoio, apenas $22 \%$ declaram ter algum tipo de auxílio institucional, tais como hospedagem, transporte, alimentação ou mesmo financeiro. Sobre as dificuldades encontradas, os aspectos mais mencionados foram o deslocamento e o período de funcionamento das turmas. Essas questões também exercem influência sobre o fluxo escolar dos cursos do Parfor, cujo índice de evasão é de $18,73 \%$ que, segundo a DEB, é inferior à tendência dos cursos regulares, mas, ainda assim, considerável.

Há, pois, deficiências na articulação entre os órgãos estaduais e municipais (secretarias de educação) e a Capes, ainda que essa seja uma das determinações tanto da Política Nacional quanto da LDBEN em relação às políticas de formação de professores: o regime colaborativo e a articulação entre os entes federados. De acordo com Montandon (2012, p. 49), revela-se primordial a necessidade de as ações serem "conduzidas de forma sistêmica entre União, Estados, Distrito Federal e municípios". Essa questão também é levantada por Scheibe (2010, p. 986):

Os entes federados não
estão, contudo,
suficientemente
articulados na execução
das políticas públicas
destinadas ao
desenvolvimento de tais
objetivos, necessários para
a valorização docente, por
meio de uma formação
mais articulada e
planejada dos quadros
para o magistério.

Entretanto, de acordo com a DEB, essas questões ligadas à permanência e entendidas como obstáculos para a participação no Parfor, após passarem por análise, seriam encaminhadas às IES e aos Fóruns Estaduais, com o objetivo de aperfeiçoar as estratégias e o desenvolvimento do Programa.

Por outro lado, levando-se em conta a literatura produzida sobre o Parfor, é possível inferir que o programa apresenta considerável potencial para contribuir com a melhoria da qualidade da educação. Valendo-se do conceito 
de Rua (2007) de que a análise dos resultados de uma política pode ser diferenciada em produto, efeito e impacto, Souza (2014, p. 650) faz a seguinte consideração:

[...] o Parfor presencial apresenta como produto a capacitação de professores em serviço por IES; como efeito, a profissionalização do professor pela obtenção da formação exigida pela lei n. 9.394 (Brasil, 1996); e, finalmente, como impacto, a melhoria da qualidade da educação básica.

Ao se examinarem os indicadores educacionais, os números mostram que, efetivamente, houve avanços em termos de capacitação docente. Os dados do INEP, por meio do Observatório do PNE, mostram que, no ano de 2009, em que se inicia o Parfor, $67,8 \%$ dos docentes da Educação Básica, pouco mais de dois terços, possuíam curso superior, e dos que possuíam, 3,2\% não eram licenciados. Os dados mais recentes, de 2014, dos quais já fazem parte alguns dos diplomados pelos cursos do Parfor, mostram que esses números subiram para $76,2 \%$, o que por si só já demonstraria algum impacto positivo dessa política. Entretanto, o percentual de professores sem licenciatura também continua a crescer, indo para $8,4 \%$. Tal fato mostra que o crescimento de docentes graduados foi acompanhado pelo aumento de profissionais sem habilitação para a docência atuando na Educação Básica. Nota-se, pois, que as estratégias de estímulo à participação de professores que necessitam ser desenvolvidas pela Capes precisam dedicar especial atenção àqueles com formação diferente da considerada adequada para a disciplina/etapa em que atuam.

\section{À guisa de síntese}

Foi possível constatar, no âmbito deste trabalho, que, assim como os demais programas lançados pela DEB, o Parfor não deixa de tocar em um ponto levantado por especialistas da área como relevante e estratégico para os enfrentamentos atuais da educação brasileira.

Contudo, essa ação constitui-se em alternativa pontual, insuficiente se consideradas as reais necessidades educacionais do país. Ainda que a seleção de projetos por editais, com apreciação pelos pares, confira transparência aos investimentos realizados, as instituições de Ensino Superior brasileiras que reúnem as condições técnicas e acadêmicas para concorrerem nos editais da Capes são poucas, fazendo com que parte considerável dos projetos se concentrem nas universidades públicas. Entretanto, a maior parte das matrículas em cursos de formação inicial de professores estão nas IES privadas, sendo grande parte delas faculdades isoladas, as quais não conseguem abrigar esses projetos.

O Parfor mostrou-se uma importante medida para a adequação da formação dos profissionais da educação, sobretudo aqueles que já se encontravam em atuação nas redes de ensino. Entretanto, a recorrência de elevada quantidade profissionais sem a formação considerada adequada para magistério é fruto da própria precarização do trabalho docente. Não entender essa política como uma medida paliativa é assumir que o déficit de professores sempre estará presente no setor educacional, dificuldade que, de fato, deve ser sanada por meio de mudanças estruturais.

Ainda que não se desconsiderem os avanços dessa e das demais políticas da DEB/Capes, programas dessa natureza efetivamse de forma fragmentada, sem atingir questões fundamentais. Ou seja, a pontualidade dessas ações na formação de professores compromete, em nível macro, a abrangência dessas políticas públicas.

\section{REFERÊNCIAS}

BRASIL. Lei no 9.394, de 20 de dezembro de 1996. Estabelece as diretrizes e bases da educação nacional. Diário Oficial da União, Brasília-DF, 23 dez. 1996. Disponível em: <http://www.planalto.gov.br/ccivil_03/leis/L9394 .htm>. Acesso em 12 fev. 2016.

BRASIL. Lei no 6.094, de 24 de abril de 2007. Dispõe sobre a implementação do Plano de Metas Compromisso Todos pela Educação, pela União Federal, em regime de colaboração com Municípios, Distrito Federal e Estados, e a participação das famílias e da comunidade, mediante programas e ações de assistência técnica e financeira, visando a mobilização social pela melhoria da qualidade da educação básica. Diário Oficial da União, Brasília-DF, 25 abr. 2007a. Disponível em: <http://www.planalto.gov.br/ccivil_03/_ato2007- 
2010/2007/decreto/d6094.htm>. Acesso em 19 abr. 2016.

BRASIL. MINISTÉRIO DA EDUCAÇÃO. O Plano Nacional de Educação - razões, princípios e programas. Brasília/MEC, 2007b. Disponível em: $<$ http://portal.mec.gov.br/arquivos/livro/livro.pd f>. Acesso em 19 abr. 2016.

BRASIL. Decreto $n^{\circ} 6.755$, de 29 de janeiro de 2009. Institui a Política Nacional de Formação de Profissionais do Magistério da Educação Básica, disciplina a atuação da Coordenação de Aperfeiçoamento de Pessoal de Nível Superior CAPES no fomento a programas de formação inicial e continuada, e dá outras providências. Diário Oficial da União, Brasília-DF, 30 jan. 2009.

BRASIL. Lei n. 12.056, de 13 de outubro de 2009. Acrescenta parágrafos ao art. 62 da Lei no 9.394, de 20 de dezembro de 1996, que estabelece as diretrizes e bases da educação nacional. Diário Oficial da União, Brasília-DF, 14 out. 2009. Disponível em: <http://www.planalto.gov.br/ccivil_03/_ato20072010/2009/lei/l12056.htm>. Acesso em 23 mar. 2016.

BRASIL. Lei n.o 12.796, de 4 de abril de 2013. Altera a Lei no 9.394, de 20 de dezembro de 1996, que estabelece as diretrizes e bases da educação nacional, para dispor sobre a formação dos profissionais da educação e dar outras providências. Diário Oficial da União, Brasília-DF, 05 abr. 2013.2 Disponível em: <http://www.planalto.gov.br/ccivil_03/_ato20112014/2013/lei/l12796.htm>. Acesso em 23 mar. 2016.

BRASIL. COORDENAÇÃO DE APERFEIÇOAMENTO DE PESSOAL DE NÍVEL SUPERIOR. DIRETORIA DE FORMAÇÃO DE PROFESSORES DA EDUCAÇÃO BÁSICA. Relatório de Gestão 2009-2014. Volumes I e II. Brasília, 2014. Disponível em: <http://www.capes.gov.br/educacao-basica>. Acesso em 15 abr. 2015.

CALDAS, A. R. Desistência e resistência no trabalho docente: um estudo das professoras e professores do ensino fundamental da rede municipal de educação de Curitiba. 2007. $160 f$. Tese (Doutorado em Educação) - Universidade Federal do Paraná, Curitiba, 2007.
FERRO, M. G. D. Plano Nacional de Formação de Professores da Educação Básica no contexto da Universidade Federal do Piauí: trajetória, desafios e perspectivas. Form@re: Revista do Plano Nacional de Formação de Professores da Educação Básica, Teresina, v. 1, n. 1, p. 44-79, jul./dez. 2013.

GATTI, B. A. Formação de Professores no Brasil: Características e Problemas. Educação \& Sociedade, Campinas, v. 31, n. 113, p. 1355-1379, out./dez. 2010. https://doi.org/10.1590/S0101$\underline{73302010000400016}$

GATTI, B. A.; BARRetO, E. S. S. Professores do Brasil: impasses e desafios. Brasília: UNESCO, 2009.

MAZZETTO, S. E.; BRAVO, C. C.; CARNEIRO, S. Licenciatura em Química da UFC: perfil sócioeconômico, evasão e desempenho dos alunos. Quím. Nova, São Paulo , v. 25, n. 6b, p. 1204-1210, dez. 2002. Disponível em: https://doi.org/10.1590/S0100404220020007000 $\underline{24}$

MONTANDON, M. I. Políticas públicas para a formação de professores no Brasil: os programas Pibid e Prodocência. Revista da ABEM, Londrina, v. 20, n. 28, p. 47-60, 2012.

PIZONI, F. Perfil socioeconômico e trajetória escolar de alunos de licenciatura em Ciências Biológicas e Matemática da Unesp de São José do Rio Preto. 2014. 139 f. Dissertação (mestrado) - Universidade Estadual Paulista, Faculdade de Filosofia e Ciências de Marília, 2014. Disponível em: <http://hdl.handle.net/11449/110483>. Acesso em: 10 out. 2017.

RABELO, R. P. Projeção da oferta de professores de matemática, física, química e biologia para educação básica no Brasil até 2028. 2015. Dissertação (Mestrado) - Escola Nacional de Estatística, Rio de Janeiro, 2015.

RISTOFF, D. I. Construindo outra educação. Florianópolis: Insular, 2011

RUIZ, A. I.; RAMOS, M. N.; HINGEL, M. Escassez de professores no Ensino Médio: soluções emergenciais e estruturais. Brasília: Câmara de Educação Básica, 2007. 
SANTOS, R. S. et al. Perfil socioeconômico e expectativa docente de ingressantes no Curso de Licenciatura em Ciências Biológicas. Reveduc, São carlos, v. 8, n. 2, p. 293-303, 2014.

SCHEIBE, L. Valorização e formação dos professores para a educação básica: questões desafiadoras para um novo plano nacional de educação. Educação \& Sociedade, Campinas, v. 31, n. 112, p. 981-1000, jul./set. 2010. Disponível em:

https://doi.org/10.1590/\$0101733020100003000 17.Acesso em: 10 out. 2017

SOUZA, V. C. Política de formação de professores para a educação básica: a questão da igualdade. Revista Brasileira de Educação, Rio de Janeiro, v. 19, n. 58, p. 629-653, jul./set. 2014. Disponível em:

https://doi.org/10.1590/S1413247820140008000 06 .Acesso em: 10 out. 2017

TORRES, J. C. et al. Formação de Professores e perfil socioeconômico de alunos de licenciatura: os cursos de Ciências Biológicas e de Matemática do Ibilce/Unesp. SIMPOED - SIMPÓSIO DE FORMAÇÃO E PROFISSÃO DOCENTE, 11, 2013, Ouro Preto, Anais... Ouro Preto: Universidade Federal de Ouro Preto - UFOP, 2013. p. 1-12.

TORRES, J. C.; PAGOTTO, M. D. S. A formação de professores na UNESP após a LDB 9394/96: velhas questões, novos desafios. CONGRESSO BRASILEIRO DE HISTÓRIA DA EDUCAÇÃO, 7, 2013, Cuiabá, Anais... Cuiabá: UFMT, 2013.

TORRES, J. C.. Perfil socioeconômico de alunos de licenciatura: alguns apontamentos. CONGRESSO NACIONAL DE FORMAÇÃO DE PROFESSORES; CONGRESSO ESTADUAL PAULISTA SOBRE FORMAÇÃO DE EDUCADORES. 2, 12, 2014, Águas de Lindóia, Anais... Águas de Lindóia: Universidade Estadual Paulista, 2012. p. 1-12.

Recebido para publicação em: 05/11/2017

Revisado em: 30/01/2018

Aceito em: 09/03/2018 